Maurer School of Law: Indiana University

Digital Repository @ Maurer Law

1995

\title{
The Adverse Testimony Privilege, Inalienable Entitlements, and the "Internal Stance": A Response to Professor Regan
}

Susan H. Williams

Indiana University Maurer School of Law, shwillia@indiana.edu

Follow this and additional works at: https://www.repository.law.indiana.edu/facpub

Part of the Family Law Commons, and the Litigation Commons

\section{Recommended Citation}

Williams, Susan H., "The Adverse Testimony Privilege, Inalienable Entitlements, and the "Internal Stance": A Response to Professor Regan" (1995). Articles by Maurer Faculty. 573.

https://www.repository.law.indiana.edu/facpub/573

This Article is brought to you for free and open access by the Faculty Scholarship at Digital Repository @ Maurer Law. It has been accepted for inclusion in Articles by Maurer Faculty by an authorized administrator of Digital Repository @ Maurer Law. For more information, please contact rvaughan@indiana.edu. 


\title{
THE ADVERSE TESTIMONY PRIVILEGE, INALIENABLE ENTITLEMENTS, AND THE 'INTERNAL STANCE': A RESPONSE TO PROFESSOR REGAN
}

\section{Susan Hoffman Williams*}

\begin{abstract}
$\mathrm{I}^{\mathrm{s}}$ $\mathrm{N}$ his article Spousal Privilege and the Meanings of Marriage, ${ }^{1}$ Mitt suggests that recent criticisms of the adverse testimony privilege fail to recognize and address the most persuasive justification for this privilege. Mitt argues that the adverse testimony privilege-unlike the privilege for confidential communications-is best understood as an expression of an "imternal" stance toward marriage. ${ }^{2}$ In this internal stance, history and counection-that is, status-give rise to obhgations independent of any specific choice on the part of the one bound. ${ }^{3}$ Marriage rests on loyalty and trust ${ }^{4}$ and leads to a blending of identity that justifies treating the married couple as a single unit of responsibility. ${ }^{5}$ If we value this internal stance, as Mitt suggests that we should, ${ }^{6}$ then we should hesitate before abandoning the adverse testimony privilege that both expresses and supports it. ${ }^{7}$
\end{abstract}

The version of the adverse testimony privilege that Mitt is considering is the traditional version, in which the witness spouse may not waive the privilege without the consent of the defendant spouse. ${ }^{8}$ Allowing the witness spouse to choose to testify - as the Supreme Court decided to do for the federal version of the privilege in United States $v$. Trammel ${ }^{9}$-would largely destroy the value of the privilege from the internal stance and transform it into an expression of the external stance. Obligation would

* Professor of Law, Indiana University School of Law.

1 Milton C. Regan, Jr., Spousal Privilege and the Meanings of Marriage, 81 Va. L. Rev. 2045 (1995).

2 See id. at $2050-51$.

3 See id. at 2086-87.

4 See id. at 2106-07.

5 See id. at $2120-23$.

6 See id. at 2049-50, 2082-87.

7 Mitt does not conclude definitively that we should keep the privilege, only that there are strong reasons for doing so that have not been adequately addressed by its opponents. See id. at $2154-55$.

8 See id. at 2054. Indeed, in some versions of the privilege, even the defendant spouse nray not waive it, i.e. adverse testimony is simply disqualified entirely. See id. at 2124-25. 9445 U.S. 40, 53 (1980). 
arise, if at all, only from an explicit choice to honor the ties of loyalty; a choice made, presumably, on tlie basis of a judgment about the worth of the relationship to the witness spouse in relation to whatever slie would give up by not testifying. Such a choice can only be made from a stance external to the relationship, a stance in which the partners' identities are distinct rather than blended. The endorsement of such a choice denies that obligation arises simply from the fact of shared experience and intimacy.

The traditional, unwaivable form of the privilege can be seen as a type of inalienable entitlement on the part of the witness spouse. Citizens generally have an obligation to give evidence when called upon to do so by the state in a criminal trial. ${ }^{10}$ Spouses, however, are given an entitlement to refuse such a call when their testimony would be adverse to the defendant spouse. Moreover, the entitlement is inalienable: it cannot be relinquished even if the witness spouse wislies to testify.

Peggy Radin has written an influential article describing an approach to assessing the justifiability of imalienable entitlements. ${ }^{11}$ This Comment will apply her analysis to the adverse testimony privilege. I beheve that two points emerge from this application. First, the internal and external stances that Mitt has identified are crucial to understanding the arguments for inalienability. Indeed, the internal stance plays the same role in this analysis that the concept of noncommodification plays in Radin's analysis of market inalienabilities. Second, of Radin's three types of arguments for inalienability, only the third-the domino theory argument-offers the possibility of a strong foundation for inalienability of this particular entitlement.

Before I begin this analysis, however, I must deal with an obvious objection to this project. Radin's article specifically addresses marketinalienability, and she goes to great pains to distinguish it from other types of inahienability. ${ }^{12}$ The adverse testimony privilege issue does not, of course, center on market-inalienability. Witness spouses do not and could not (for reasons completely separate from the internal stance) seek to sell their testimony for money. But they do sometimes wisl to trade that testimony to the prosecution in exchange for more lenient treatment for themselves. The adverse testimony privilege is, thus, a kind of inalienability, but not a market-inalienability, so it is not clear why Radin's analysis would apply here at all.

10 See United States v. Nixon, 418 U.S. 683, 709 (1974) ("the public . . . has a right to every man's evidence") (citations omitted).

11 Margaret J. Radin, Market-Inalienability, 100 Harv. L. Rev. 1849 (1987).

12 See id. at 1852-55. 
There are two responses to this objection. First, the hberal philosophy that Radin identifies as underlying the push toward commodification ${ }^{13}$ has much in common with the external stance that Mitt sees as the foundation for criticism of the adverse testimony privilege. ${ }^{14}$ Although they are not identical, they share a focus on persons as conceptually distinct from the characteristics and relationships that make them particular individuals ${ }^{15}$ and as fundamentally constituted by their capacity for choice. ${ }^{16}$ In other words, the move to abandon inalienability in both cases arises from a similar constellation of assumptions. As a result, it is reasonable to think that the arguments in response to this move might have something in common as well. Second, the proof of the applicability is in the apphication. That is, if the analysis using Radin's categories sheds interesting hight on Mitt's arguments, that should be sufficient proof that those categories are relevant here as well.

\section{The Prophylactic Argument}

The first kind of argument that Radin identifies in support of inalienability she calls the "prophylactic" argument. ${ }^{17}$ The prophylactic argument begins by recognizing that even if we wish to allow voluntary transfers of an entitlement, we do not want to allow coerced or involuntary ones. The difficulty is that sometimes we do not trust ourselves to distinguish between the voluntary and involuntary ones. Such distrust of our abilities would not generally justify making the entitlement inalienable, but it may do so if the costs of the inevitable involuntary transfers that shp through outweigh the benefits of the voluntary ones. This imbalance could occur if voluntary transfers of the entitlement are extremely rare (i.e. most people would not give it up willingly) or if the cost of a coerced transfer is very high (i.e. the entitlement is an extremely important one to most people). In this situation, we are justified in prohibiting the (few) voluntary transfers as a way of preventing the inevitable and very costly involuntary ones. ${ }^{18}$

The prophylactic argument will not work very well as a justification for the inalienability of the adverse testimony privilege. First of all, it is far from clear that the overwhelming majority of spouses who find themselves in this situation would choose not to relinquish this entitlement. Mitt identifies a variety of reasons for wishing to testify, including: the

13 See id. at 1887-1903.

14 See Regan, supra note 1, at 2067-79.

15 Compare Radin, supra note 11, at 1891-98, with Regan, supra note 1 at 2067-70.

16 Compare Radin, supra note 11, at 1898-1903, with Regan, supra note 1, at 2073-77.

17 See Radin, supra note 11, at 1909.

18 See id. at 1909-10. 
desire to get an advantageous plea bargain from the prosecutor for one's own participation in the crime; the failure of the marriage; the desire to support one's conception of justice, particularly if one's own participation was coerced; and, of course, simple spite. ${ }^{19}$ Indeed, in light of the very substantial benefits to be realized from testifying, it is extremely unlikely that most people would choose not to testify unless something very large and significant were at stake on the other side. That something is, of course, the value of the marriage from the internal perspective: the loyalty, trust, and sense of identity that would be forfeited by testifymg adversely to one's spouse. It is, I think, extremely plausible to claim that if a person adopts this internal perspective, the harm from being coerced into violating this trust would in fact be enormous. Thus, a powerful argument can be made for avoiding involuntary transfers of this entitlement. The problem, however, is that voluntary transfers will only be rare if most people have in fact adopted this internal stance with respect to their marriages. If, on the other hand, most people-or at least most people under these extreme circumstances-would wish to adopt the external stance toward their marriage, then we will be prohibiting inany voluntary transactions in order to prevent the few involuntary ones.

Inalienability might still be justified if the extremely large cost to those few who are coerced into involuntary transfers outweighs the benefits to the inany who might choose to testify. This justification for inalienability is only workable, however, if making the entitlenent inalienable actually relieves the burden on the coerced group. If the coerced few are no better off under a system where their entitleinent is inahenable than under one where it is alienable, then the costs to them could hardly justify inalienability.

The difficulty is that inahenability here raises a double-bind issue. Radin describes a double-bind as a situation in which the background constraints operating on a person create a dilemma in which both free transferability and inalienability lead to oppressive results. ${ }^{20}$ Radin illustrates the double-bind with the exainple of women who are coerced into prostitution by poverty and lack of alternatives. If we allow the person to transfer the entitlement under this tremendous pressure (i.e. to sell her sexual services), then she loses this thing that she greatly values. If we do not allow the transfer (i.e. outlaw prostitution), but do nothing to relieve the background pressure (of poverty), then we have taken away what she

19 See Regan, supra note 1, at 2134-40.

20 See Radin, supra note 11 , at 1915-17. 
believes to be her best option under these difficult circumstances. Either way, slie loses. ${ }^{21}$

Spouses subject to the adverse testimony privilege face such a doublebind. When subjected to the pressure to testify from a prosecutor, a spouse might feel coerced into giving up her privilege in exchange for her freedom. If she is a person who values the internal stance toward her marriage, then she would have been forced to pay a terrible price. But taking that choice away from her does not necessarily improve her condition. Indeed, the fact that she would choose to testify is some indication that she views it as the best option available to her. By making the entitlement inalienable, we have, arguably, simply imposed even greater coercion on this unfortunate person.

While any spouse could be subject to this double-bind, the underlying constraints that generate the double-bind in this area make it more likely that women will find themselves with these limited and unacceptable options. These underlying constraints consist of a collection of conditions relating to gender inequality. For example, most criminal defendants are men, so women are far more likely to find themselves in the position of the witness spouse being restrained by an inalienability rule than in the position of a defendant spouse benefiting froin it. ${ }^{22}$ To compound the inequahty, gender roles in our society may make women more likely than men to take an internal view of marriage. ${ }^{23}$ As a result, women would be more likely than men to experience the transfer of this entitlement as a very large loss. Finally, the rules of duress may not adequately recognize the power differential between many husbands and wives and may therefore leave women subject to prosecution-and to coercion to testifywhen they should not be. ${ }^{24}$

Radin and Mitt both argue that the existence of such a double-bind creates an obligation to address the underlying conditions rather than simply relying on inalienability rules to deal with the resulting pressures. $^{25}$ But, as both realize, some of these conditions are very deep in our culture and wide-reaching. They would be difficult to alter even with the strongest commitinent, and it is not at all clear that we are strongly committed as a society to ending gender inequality. As a result, we must decide low to handle the inalienability issue under the present, imperfect conditions, even while we work to alter those conditions.

21 Id.

22 See Regan, supra note 1 , at 2095 \& n.236.

23 See id. at 2071-73.

24 See id. at 2145-46.

25 See Radin, supra note 11, at 1911, 1917; Regan, supra note 1, at 2145-47 (on changing the definition of duress). 
Mitt's section on disparate gender impact ${ }^{26}$ is an attempt to assess this inalienability rule from the perspective of the double-bind in our imperfect world. He argues that the impact on the witness spouse is relatively small and that the privilege does not itself contribute to the underlying gender inequality. ${ }^{27}$ Nonetheless, the privilege plainly has the impact of disadvantaging women more than men under present conditions. The question posed by the double-bind is whether abandoning inalienability would lead to less disadvantage for women relative to men.

If women continued to adopt the internal stance toward marriage with greater frequency than men, then allowing alienability of the entitlement not to testify would disadvantage them relative to men because they would find themselves coerced into violating their own sense of loyalty and joint identity. We could, and probably should, try to determine whether this disadvantage is worse than the disadvantage created by inalienability, but there is another possibility that makes our task somewhat easier.

It is possible, indeed it is central to Mitt's argument, that abandoning inalienability here could lead to abandoning the mternal stance itself. ${ }^{28}$ If women stopped adopting the internal stance, however, that might contribute to a shight increase in equality between women and men. With respect to criminal testimony, women would still suffer from all of the other relevant disadvantages, but at least they would no longer face the additional loss of loyalty and identity that men generally do not face. In addition, with respect to marriage more generally, women might be better off relative to men if they did not adopt the internal stance, given that men are less likely to do so. If the abandonment of inalienability would contribute to women adopting an external stance, that might improve their lot overall. ${ }^{29}$

Thus, the prophylactic argument leads back, I think, to alienability because of the extent to which the external stance has permeated our culture. To summarize: the prophylactic argnment will justify inalienability only under certain conditions. First, a voluntary transfer should be a

26 Regan, supra note 1, at 2144-53.

27 See id.

28 See id. at 2108-11, 2125-34.

29 This is a classic prisoner's dilemma situation. Let's say that women (and men) would be best off if both genders adopted an internal stance. Nonetheless, if only one partner adopts that stance, then she is likely to be worse off than if neither does. Since the present case is the worst scenario for women, a world in which both adopt the external stance is an improvement for women. Obviously, a world in which both adopt the internal stance might be even better, but it is fairly clear that the entitlement at issue here cannot achieve that result. The traditional privilege was inalienable but did not succeed in getting men generally to adopt the internal stance to marriage. 
truly rare case. But here, the widespread adoption of the external stance, coupled with the strong incentives to testify, suggest that would not be so. Second, the involuntary transfers inust impose a very large cost that could be alleviated by inalienability. But an analysis of the double-bind suggests that inalienability is no better than alienability from the perspective of the primary group subject to the double-bind here. Indeed, it is possible that alienability might lead to an abandonment of the internal stance which could actually reduce women's overall inequality.

It should not be surprising that the prophylactic argument is not particularly successful. The distinctive feature of this argument is that it does not question the assumptions underlying the push toward alienability in general. ${ }^{30}$ In other words, the prophylactic argument accepts the centrality of choice. If Mitt is correct that the adverse testimony privilege rests on a rejection of choice as the sole foundation for moral obhgation, then it makes sense that this argument will not in the end support that privilege.

\section{The Prohibition Argument}

Let us turn, then, to the second type of argument that Radin identifies: the prohibition argument. According to the prohibition argnment, alienability can turn an entitlement into a new and different thing, a thing so bad that it simply should not exist. ${ }^{31}$ In the case of inarket-inalienability, the argument centers on commodification: treating things as commodities to be bought and sold in the market. Radin gives the example of commodified sex as something that our culture beheves to be very different froin and inferior to non-commodified sex. We might inake sexual relations market-malienable in an attempt to prohibit this commodity from existing. ${ }^{32}$

In the context of the adverse testimony privilege, we are not dealing with inarket-alienability and the resultant commodification. But if we ask what is created by allowing the witness spouse to choose to testify, we nay discover that inalienability serves the purpose of prohibiting that "thing" from existing. The "thing" at issue here is, I beheve, the external stance that Mitt identifies. If the witness spouse chooses whether or not to testify, that very act of choice constitntes the adoption of the external stance toward the marriage. ${ }^{33}$ One reason why we might make the entitlement inalienable would be to prevent people from taking this stance.

\footnotetext{
30 See Radin, supra note 11 , at $1909-10$.

31 See id. at 1912 .

32 See id. at 1921.

33 See Regan, supra note 1, at 2103-04.
} 
Mitt is not, however, suggesting that the external stance toward marriage is necessarily a bad thing. Particularly when viewed from the perspective of women, that stance may be a necessary tool for dealing with potentially oppressive relationships. ${ }^{34}$ Thus, Mitt is not suggesting that we ought to try to prohibit the existence of the external stance in general. ${ }^{35}$ The question, then, is whether the adoption of this stance in the case of criminal testimony constitutes a thing we might wish to prohibit even if the adoption of it in other circumstances does not. ${ }^{36}$

Mitt's discussion of the privilege as creating a taboo appears at first glance to make this argument. ${ }^{37}$ Most people would find the public spectacle of one spouse helping to convict another highly distasteful. Our distaste could be understood as reflecting exactly this judgment that taking an external stance toward one's marriage in these circumstances is particularly objectionable. While we may find it acceptable for spouses in many instances to refuse to acknowledge obligations based on status, we are more troubled when that refusal leads to a public betrayal of trust and the serious consequences of criminal conviction. The privilege could be a way of saying that although the external stance is fine in some circumstances, it is a bad thing here.

Although this is a plausible argument, I believe it is ultimately mistaken. The repulsion we feel at the spectacle of one spouse helping to convict the other rests on a collection of assumptions about the nature of their relationship and their motives. We are assuming, for example, that the defendant spouse trusted and relied on the witness spouse and that the witness spouse is acting out of selfish motives in betraying that trust. Where those assumptions are shown to be untrue, I suspect that most people would find the testimony of the witness spouse to be justified, perhaps even laudable, rather than repulsive. ${ }^{38}$

In other words, our judgment about when the external stance is appropriate turns on a whole collection of factors and the criminal trial context of this privilege is relevant only to some of those factors. As long as we continue to believe that the external stance is itself a valuable part of the

34 See id. at 2071-73.

35 Indeed, he recognizes that the trend in much of family law is plainly toward allowing people to take an external stance toward their family relationships. See id. at 2073-77.

36 Radin raises a similar issue when she points out that commodification is not a per se evil, either; we do not wish to prohibit the commodification of nuts and bolts, even if we do wish to prohibit the commodification of sex. See Radin, supra note 11, at 1912.

37 See Regan, supra note 1 , at 2129-31.

38 Mitt's very interesting discussion of the state's interest in promoting a citizen's loyalty to justice over her loyalty to particular individuals provides one possible explanation for this shift in perception. Id. at 2142-43. 
marital relationship, issues like the nature of the relationship and the parties' motives will be relevant to the determination of when that stance is appropriate. And as long as those factors are relevant, we cannot rely on a criminal trial context alone to justify the clain that the external stance adopted by a witness spouse is such a bad thing that it should simply be prohibited.

In any event, I don't beheve that this prohibition argument is the point in Mitt's discussion of the function of a taboo. He does report the repugnance most people feel for the act of the witness spouse, but he is not concerned to show that each such act is soinething we should seek to prohibit from existing. Instead, the focus of his argument is on the function of the taboo in maintaining a particular view of marriage: the internal stance, itself. ${ }^{39}$ The important point is not how bad the external stance is, but how valuable the internal stance is, and how important the privilege is to its maintenance.

\section{The Domino Theory Argument}

Mitt's discussion of taboo is what Radin would call a "domino theory" argument, rather than a prohibition argument. In the market-malienability context, the domino theory argument says that allowing the commodified form of the entitlement will destroy the non-cominodified forms. ${ }^{40}$ For example, allowing full commodification of sex could make it difficult or impossible for people to conceive of any sexual relations in a noncominodified way. ${ }^{41}$

In the context of the adverse testimony privilege, the domino theory argument says that allowing the witness spouse to take an external perspective here-by giving her the choice whether to testify-could make it difficult or impossible for people to adopt the internal stance with respect to marriage more generally. The goal is not to destroy the existence of the external stance in this context (as in a prohibition argument), but to preserve the possibility of the internal stance in a whole host of contexts.

Mitt's discussion of the function of taboo is a dommo theory argument. The point is to demonstrate the way in which the adverse testimony privilege supports the existence of the internal stance generally and the risk that legal abandonment of the privilege poses to that stance. The taboo argument appears in a section discussing how and to whom the message of the privilege is transmitted. ${ }^{42}$ Mitt argues that the abohition of the

\footnotetext{
39 See id. at 2128-30.

40 See Radin, supra note 11 , at 1912-14.

41 See id. at 1922.

42 Regan, supra note 1 , at $2125-34$.
} 
privilege could receive wide public attention in the context of a trial in which spousal testimony was crucial to conviction. Such attention could seriously undermine people's perception of the moral demand for spousal loyalty. The function of inalienability here is to prevent the slide into the external stance that could be generated by allowing alienation of this entitlement. ${ }^{43}$

This domino theory argument is the lieart of the paper. It represents the relationship between law and culture that Mitt is seeking to explore through the privilege. ${ }^{44}$ The reason that the domino effect is a threat is that law both expresses and shapes culture. The present rule reflects our longstanding-if somewhat ambivalent-commitment to the internal stance toward marriage. A change in this legal rule could contribute to the gradual cultural slift toward the external stance identified by Mitt. If law and culture were not interrelated in this way, then there would be no risk to the internal stance, generally, from the abohtion of this particular privilege. ${ }^{45}$

This domino theory argument is the strongest argument for retaining the privilege. Where the prophylactic argument takes for granted the centrality of choice that is fundamental to the external stance, and the prohibition argument seems to rely on a too-complete rejection of the external stance, this argument focuses on the value and fragility of the internal stance. It responds directly to the primary concern underlying the privilege - the internal stance that Mitt has identified-without needing to deny the value of the external stance. It is the argument that best fits the inalienability at issue here, and it is an argument that makes sense ouly once Mitt has defined the internal stance and its relation to the privilege.

As Mitt recognizes, however, this argument is vuhierable because it is highly empirical. ${ }^{46}$ The domino effect depends on who discovers the alienability of the privilege and how it actually changes them, if at all. As Radin points out in her discussion of this argument, we must be careful

.43 Mitt recognizes that the privilege may be only one small part of a collection of legal rules that serve this purpose. Other rules may be more important to the maintenance of the internal stance in a practical sense: unlike the adverse testimony privilege, they may actually shape people's everyday behavior. See id. at 2132 . Nonetheless, he argues that the privilege has symbolic significance for maintaining the internal stance and that the abolition of the privilege could send a very powerful symbolic message. See id. at 2129.

44 See id. at 2050-51. This relationship is also a central theme in Radin's article. See Radin, supra note 11, at 1877-87 (discussing the interdependence of discourse and reality).

45 Some legal rules may have such a large practical role in people's lives that we do not need to look at the relationship between law and culture to explain their impact. That is not, however, the case with this privilege.

46 See Regan, supra note 1 , at 2131-32. 
not to assume a domino effect but to examine the evidence available to see if one is actually likely to occur. ${ }^{47}$ Mitt does indeed attempt to describe, in a very specific way, how such an effect might come to pass and why it seems likely that it would. ${ }^{48}$ I would simply like to raise one additional issue that bears on this question of whether the loss of inalienability here would meaningfully compromise the internal stance on marriage.

The existence and nature of the spousal cominumications privilege is relevant to the impact of making the adverse testimony privilege alienable. As Mitt points out, the communications privilege, while fundamentally consistent with the external stance, contains elements of the internal stance as well. ${ }^{49}$ The most obvious and important of such elements is the fact that it is limited to spouses. Tying the privilege to status suggests that the reason for granting this entitlement not to testify is not simply the choice of the parties to share a confidence. If that were a sufficient basis, then the privilege should be available to any two people who consent to such a sharing. The fact that it is only available to married couples ${ }^{50}$ suggests that this status provides part of the justification. This suggestion is strengthened by the presumption that comınumications within a marriage are confidential..$^{51}$

The communications privilege is, in other words, a compromise between the external and internal stances. In the market-inalienability context, Radin calls such compromises incomplete cominodification. ${ }^{52}$ In the context of spousal privilege, in hight of Mitt's analysis, we might call it incomplete externalization. The mixed nature of the communications privilege raises two possibilities that need to be addressed before the domino theory argument can succeed. First, does the cominunications privilege in its present form provide sufficient support for the internal stance that that stance would not be harmed (or not hanned much) by the

47 See Radin, supra note 11, at 1914.

48 See Regan, supra note 1, at 2125-29.

49 See id. at 2091-92.

50 And, in a parallel form, to people in certain other status relationships, such as doctor/ patient, attorney/client, and priest/penitent.

51 See Regan, supra note 1, at 2096-97. The inalienability of this privilege is not, however, an elenient inconsistent with the external stance. But see id. at 2091-92. If the parties did in fact consent to share a confidence, then one party is perfectly justified in holding the other to that agreenient later. In other words, enforcement of contracts is supported by (rather than inconsistent with) an enphasis on individual choice. See generally Charles Fried, Contract As Promise: A Theory of Contractual Obligation (1981) (arguing that within a liberal individualist approach, contracts-and promises generallyare legitimate self-imposed obligations).

52 See Radin, supra note 11, at 1917-21. 
shift to an alienable adverse testimony privilege? To put the question more pointedly: Even if the privileges were both predominantly external in orientation, would the simple fact that they are tied to marital status continue to provide sufficient support for the internal stance?

Although I think that further analysis of this issue would strengthen the domino theory argument, Mitt does provide the necessary response. ${ }^{53}$ Whatever support the spousal nature of the privileges might offer would be swamped by the perception that we are abandoning the internal stance by altering the adverse testimony privilege. Perhaps the fact that the privileges are limited to spouses would have been sufficient to support the internal stance if we had never had an inalienable adverse testimony privilege. But the shift to an alienable privilege will send such a loud message of abandonment that it will drown out the quiet background hum of support that remams. ${ }^{54}$ We must, in other words, assess the domino effect in terms of the impact of changing the privileges we have now, not in terms of some privilege arrangement viewed in the abstract.

The second possibility we must consider is whether there are ways of modifying either privilege to enhance their joint protection of the internal stance and thereby counteract the effect of inaking the adverse testimony privilege ahenable. For example, the presumption that inarital commumcations are confidential could be strengthened by inaking it irrebuttable in certaim circumstances (perhaps where the commumication takes place in the marital horre with no one else present). This change would send the message that spouses must accept and honor certain confidences simply by virtue of their status, rather than because of any hypothetical choice they could exercise on each particular occasion. Or we could make the adverse testimony privilege alienable only under certam limited circumstances in order to reheve the worst pressures of the double bind. For example, we could allow a spouse to testify only if she is herself threatened with prosecution and she has minor children who would be left without their primary caretaker if she is incarcerated. ${ }^{55}$ Such limits would send the message that we still value spousal loyalty very highly, but we believe that certaim other values are equally important. ${ }^{56}$

53 See Regan, supra note 1, at 2128-29.

$54 \mathrm{Cf}$. id. at 2130-31 (arguing that, in the analogous case of babyselling, "[t]he movement from prohibition to choice .. . thus itself might send a message more powerful, and dramatically different, than prohibition sends on its own").

55 Given that most primary caretakers are women, this modification would also go a small distance toward rectifying the gender imbalance in the privilege.

56 There are, admittedly, practical difficulties with these suggested modifications. For example, the latter suggestion might create an incentive for prosecutors to charge innocent spouses in order to put them in the position where they are allowed to alienate their entitlement. (It is worth noting that the same incentives are created by full alienability.) 
This second alternative asks whether-even assuming that we are seeking to support the internal stance-maintaining inalienability of the adverse testimony privilege is the best path to our goal. Perhaps other changes in the privileges could provide the necessary support while alleviating some of the difficulties caused by inalienability. Perhaps a shightly different balance between internal and external stances would be an overall improvement. If so, then the domino effect need not occur as long as we connect the move to alienability to some of these other changes. ${ }^{57}$

\section{ConCLuSION}

The move to modify the adverse testimony privilege has focused not on abohishing the privilege entirely, but on giving the witness spouse the choice whether to testify. The discomfort with this privilege has centered, then, on its inalienability. Mitt has demonstrated the way in which the privilege rests on a certain conception of marriage and of the stance a spouse ought to take toward it: the internal stance. Assessing the malienability of the privilege with the help of Radin's collection of arguments highlights the importance of Mitt's insight. One must recognize the role and relevance of the internal and external stances in order to apply all three of the types of arguments for inalienability. Indeed, the internal stance plays the same role in the analysis of the inalienability of this privilege that the resistance to cominodification plays in the analysis of market-inalienabilities.

When seen from this perspective, the strongest argument for the traditional privilege appears to be the threat posed by its alteration to the continued vitality of the internal stance generally. This domino theory argument, however, requires a highly empirical and contextual analysis with no clear boundaries. As a result, we are left, as Mitt concludes, not with a clear endorsement of the privilege, but with a powerful image of what we may risk by eliminating its inalienability. ${ }^{58}$

The point here is not to advocate any particular modification of privilege law, but to offer illustrations of forms of incomplete externalization, see supra note 52 and accompanying text, that might alleviate the domino effect.

57 In the spirit of pragmatism, this analysis must also take account of the actual likelihood of legislatures adopting these other changes.

58 See Regan, supra note 1, at 2154-55. 
